correlated with the superior water-holding capacity of the mound of organic debris accumulated by Franseria, but not by Encelia.

The apparently contradictory results of laboratory and field tests in this type of investigation may be due to the fact that all the toxic substances present in the substrate are available to the test species during the laboratory experiment when extracts or milled plant material are used. In our opinion such substrates are not comparable with plant litter, for it has been found in a replicated experiment that Araucaria seeds fail to germinate on substrates of milled Backhousia leaves enclosed in Petri dishes, but under the same conditions germination is not significantly reduced (although it occurs more slowly than the controls) on substrates of the same intact leaves containing $4 \cdot 1$ per cent of dehydroangustione.

In our opinion, the experiments outlined above emphasize the dangers of arguing, without further experimentation in the field, that the 'antibiotic effects' demonstrated in simple laboratory tests operate in natural plant communities.

Full details of this work will be published elsewhere.

$$
\begin{aligned}
& \text { J. R. CaNnON* } \\
& \text { N. H. CorbetT } \\
& \text { K. P. HAYdock } \\
& \text { J. G. TraceY } \\
& \text { L. J. WebB }
\end{aligned}
$$

Commonwealth Scientific and Industrial Research Organization,

$$
\text { Australia. }
$$

* Present address : Chemistry Department, University of Western Australia, Nedlands.

${ }^{1}$ Bonner, J., Bot. Rev., 16, 51 (1950).

${ }^{2}$ Penfold, A. R., J. Proc. Roy. Soc. N.S.W., 57, 300 (1923). Birch, A. J., and Ëlliot, P., Austral. J. Chem., 9, 95 (1958)

8 Went, F. W., Bull. Torrey Bot. Club, 69, 100 (1942).

- Gray, R., and Bonner, J., Amer. J. Bot., 35, 52 (1948); J. Amer. Chem. Soc., 70, 1249 (1948).

'Muller, C. H., Amer. J. Bot., 40, 53 (1953). Muller, W. H., and Muller, C. H., ibid., 43, 354 (1956).

\section{Sorbitol Metabolism in Apple Fruits}

SoRBITol is a polyhydric alcohol found commonly in the Rosaceae : in apples it can constitute a large proportion of the dry matter. Little is known, however, of its metabolism in higher plants. Edson ${ }^{2}$ referred to a sorbitol dehydrogenase in animals and micro-organisms and mentioned a similar occurrence in plants.

I have been able to show that, when an aqueous extract of an acetone powder preparation from the fruit cortex of apples (var. Miller's Seedling) was treated with sorbitol in the presence of boiled yeast extract, an acid-labile non-reducing sugar was formed. The sugar was probably sucrose and the normal yield was 1--2 mgm. from $10 \mathrm{mgm}$. sorbitol (at about $20^{\circ} \mathrm{C}$.), with due allowance for the sucrose in the yeast extract.

These results were repeatable up to two months after preparation of the acetone powder. It then became inactive, and more detailed examination of the enzyme system involved in this reaction will be made when a further crop of fruit is available.

\section{A. R. N. GORROD}

East Malling Research Station, Maidstone, Kent.

${ }^{1}$ Edson, N. L., Aust. N.Z. Assoc, Adv. Sci., 29, 281 (1952),

\section{BACTERIOLOGY}

\section{Association of a Steroid and a Pigment with a Diffusible Fruiting Factor in Myxococcus virescens}

A DIFFUSIBLe factor inducing fruiting-body formation in Myxobacteria has been demonstrated by Lev ${ }^{1}$. In an attempt to identify further such a factor in Myxococcus virescens, an aqueous extract of fruitingbodies was concentrated by drying from the frozen state.

Using a medium which would permit the swarming of vegetative cells, but not the formation of fruiting bodies, under normal conditions, consisting of $1 / 100$ concentration routine meat-extract agar, with 3 per cent non-nutrient agar and 0.001 per cent sodium chloride, four circular wells were made on a plate supporting a film of vegetative cells, and this was incubated for a further 7 days to obviate any effects of mechanical disturbance. A few drops of extract were placed in two of the wells, with distilled water in the two control wells. After 8 days incubation at $30^{\circ} \mathrm{C}$., small fruiting-bodies could be discerned around the wells containing the extract.

Comparison of descending chromatograms of the two extracts showed the existence of a spot on the chromatogram of the fruiting-body extract which was absent from that of the vegetative cells. This spot was associated with the pigment of the fruitingbodies ; it reacted with Liebermann's reagent and is therefore presumed to contain a steroid.

A further experiment in which actual portions of the chromatogram paper were laid on the plate showed that fruiting-body formation was induced in the vicinity of the pigmented spot.

\section{J. JenNINGs}

Department of Bacteriology,

University of Birmingham.

${ }^{3}$ Lev, M., Nature, 173, 501 (1954).

\section{Accumulation of Indole Compounds in Cultures of Chromobacterium violaceum}

SuBSTANCEs yielding a typical indole test with $p$-dimethylaminobenzaldehyde (Ehrlich reagent) were recently observed in peptone broth cultures of gelatinous strains of Chromobacterium violaceum ${ }^{1}$. The nature and the origin of the substances giving the pink-red colour with Ehrlich reagent was of some interest because the species has been reported to lack the enzyme tryptophanase ${ }^{2}$ and the genus as a whole is generally considered to be indole-negative ${ }^{3}$, which implies inability to degrade tryptophan to indole.

Employing the Ehrlich reagent and technique described by Skerman ${ }^{4}$, several cultures of gelatinous Chromobacteria were tested for indoles after growth for 5 days at $30^{\circ} \mathrm{C}$. in several media. The results shown in Table 1 indicate that the largest accumulation of indoles occurred in 'Bacto' peptone broth containing glucose and incubated under aerobic conditions. 'Bacto' tryptone, which contains more tryptophan than peptone ${ }^{5}$, did not allow indole accumulation. When 0.5 per cent $(w / v)$ tryptophan was added to peptone broth no increase in the amount of Ehrlich-positive substances was observed. Synthetic glucose-ammonium salts medium with or without added yeast extract $(0.02$ per cent) invariably failed 